\title{
Matías Romero y el oficio diplomático: 1837-1898, Sergio Silva Castañeda y Graciela Márquez Colín, México, Secretaría de Relaciones Exteriores-Instituto Matías Romero, 2016, 118 pp.
}

\section{MATÍAS ROMERO: MODELO DE DIPLOMÁTICO PARA EL ENTORNO ACTUAL}

Diversos avatares ha afrontado México en su vinculación con los Estados Unidos desde su génesis como nación independiente hasta la actualidad. La primera representación plenipotenciaria conferida por sus respectivos gobiernos a Joel R. Poinsett y José Manuel Zozaya Bermúdez es la piedra de toque de una relación diplomática con alta prioridad para nuestro país. En las casi dos centurias que desde entonces acumula esa bilateralidad compartida transitan tanto agendas de prioridades múltiples y divergentes, como acres sucesos históricos o episodios de atemperación donde el ejercicio diplomático ha sido predominante.

En los albores de un nuevo episodio de las relaciones mexicano-estadunidenses, Graciela Márquez y Sergio Silva nos presentan la obra biográfica de uno de los representantes diplomáticos más eminentes que ha tenido México: Matías Romero Avendaño (1827-1898). Esta obra, publicada por la academia diplomática mexicana que lleva el nombre de este insigne personaje, desglosa aspectos fundamentales de su vida, haciendo énfasis en su labor como diplomático, tarea que desempeñó, de forma discontinua, por más de dos décadas. La develación de su vida y trayectoria profesional está sustentada en correspondencia y documentación oficial, así como en documentos utilizados en obras previas.

La obra no es exhaustiva, es más bien un esbozo biográfico que se centra en la labor diplomática de Romero Avendaño y en el papel que, gracias a su conocimiento del sistema internacional, desempeñó en otras facetas de su vida, específicamente como empresario y como secretario de Hacienda. Este aspecto no va en detrimento de su contenido, por el contrario la selección de los pasajes es meticulosa y precisa, garantizando la plena descripción de quien los autores consideran "un diplomático muy hábil en un entorno internacional sumamente complicado”.

Oriundez y forja académica son aspectos determinantes durante su vida profesional. Oaxaca y el Instituto de Ciencias y Artes de Oaxaca (ICAO) acercaron a Matías Romero a personajes ilustres que determinaron su sino en la administración pública nacional: Benito Juárez, como gobernador durante su ingreso a ese instituto y Porfirio Díaz como profesor en el mismo. El primer fruto de estas vicisitudes fue su ingreso en 1855, a los 18 años, a la Secretaría de Relaciones Exteriores -sección de Europa- a partir de un nombramiento "meritorio” que le instruyera el presidente Juan Álvarez al entonces canciller Manuel María Arrioja. De esta forma, Matías Romero formó parte de esa ola oaxaqueña que llegó al poder encabezada por Juárez y cuya influencia, en gran medida, sería evidente hasta más de medio siglo después. 
Su primer andar en la diplomacia mexicana refleja la realidad de un servicio diplomático que no obstante haber emergido inmediatamente después de la independencia nacional, tardo más de un siglo en configurar fisonomía y preceptos propios. El reclutamiento basado en recomendación implicaba no percibir emolumentos y un alto sacrificio en nombre de la institución y del país. Se requería, además de conocimientos en idiomas y asuntos internacionales, gran voluntad y decisión para avanzar profesionalmente. Así, los primeros años de Matías Romero como diplomático tuvieron como rasgo tanto la penuria económica como la búsqueda constante de alguna oportunidad laboral en el exterior.

Ante el segundo gran cisma histórico de la vida nacional durante el siglo XIX -Guerra de ReformaRomero respalda la causa liberal y ante ello los autores dejan como interrogante si lo hizo convencido de esos ideales o como gesto solidario a sus mentores. Al margen de los motivos reales, lo que reivindica esta obra es la afinidad católica de Matías Romero, rasgo común entre todos los liberales, para lo cual refiere los lemas utilizados con su firma en los documentos que suscribió durante esos años: "Dios y Libertad”, que era común entre los egresados del ICAO; "Dios, Libertad y Reforma”, o "Libertad y Reforma”. A la par de la conflagración interna, durante el gobierno itinerante de Benito Juárez, Romero trabajó al lado de Melchor Ocampo, consiguiendo ascensos expeditos: paso de escribiente a oficial segundo en menos de un año, con lo cual es evidente que ese acontecimiento bélico repercutió favorablemente en su carrera.

Como durante este período una de las claves para el gobierno de Juárez fue la relación con Estados Unidos, se diseñó una estrategia en la cual Ocampo y Romero desempeñaron un rol fundamental. Particular atención otorga esta obra al contacto directo, y a las consiguientes recomendaciones hechas por ambos personajes respecto a la postura de los partidos demócrata y republicano en el vecino país: el primero con intereses esclavistas y expansionistas bien representados, mientras que el segundo en plena consolidación tras la debacle del partido Whig, y por ello con mayores expectativas de negociación.

En esta disyuntiva, Robert M. Mc Lane, representante del presidente James Buchanan, viajó a Veracruz para reconocer al gobierno de Juárez e inmediatamente después inició negociaciones diplomáticas con Melchor Ocampo para la suscripción de un acuerdo, que culminó en diciembre de 1859 con varias concesiones, entre la que destacaba el derecho de tránsito a perpetuidad por el istmo de Tehuantepec. Aunque el acuerdo no fue ratificado por los Estados Unidos, representa un modelo de negociación diplomática. A pesar del debilitamiento frente a las fuerzas conservadoras y una creciente amenaza de potencias extranjeras en ultramar, se obtuvo el reconocimiento diplomático durante los peores momentos de la Guerra de Reforma, ello sin hacer todas las concesiones que el gobierno estadunidense solicitaba: cesiones territoriales, derechos de tránsito, pago de reclamaciones, entre otras. Aunque resulta difícil identificar el papel preciso que Matías Romero desempeñó en la concreción del convenio, lo único cierto es que siempre estuvo cerca de Melchor Ocampo y trató directamente con McLane y su comitiva, lo cual constata su pericia diplomática. 
El adagio que versa "el diplomático no nace, se hace”, se confirma con Matias Romero. Antes de la suscripción del acuerdo McLane-Ocampo fue enviado a Washington para dar seguimiento a su respectiva aprobación en las instancias legislativas de aquel país. Así, asistió a debates, tejió una amplia red de contactos, visitó parte del país y estudió a fondo su sistema político. Mientras eso sucedía, el titular de la legación de México en ese país, José María Mata, volvió a nuestro país y Matías Romero, con entonces 23 años, asumió como encargado de negocios. Coincidió con el triunfo de Abraham Lincoln como presidente de ese país, con quien el diplomático mexicano se entrevistó en diversas ocasiones, incluso antes de su toma de posesión, atendiendo instrucciones de Benito Juárez. Las afinidades que fueron germinando con el mandatario estadunidense, quien consideraba la relación con el gobierno de Juárez "la más interesante e importante en el círculo completo de sus relaciones internacionales”, no llegaron a rendir frutos debido a las coyunturas internas que afrontaron ambos países y el primer ciclo de Matias Romero en los Estados Unidos concluyó en junio de 1863. No transcurrieron más que algunos meses, cuando Juárez lo devolvió a ese país, aunque esta vez con el cargo oficial de enviado especial y ministro plenipotenciario.

Aunque el núcleo del texto es el desempeño diplomático, también refiere el tránsito de Matías Romero como titular de la Secretaría de Hacienda, cargo que desempeñó por primera vez de 1868 a 1872 (bajo el gobierno de Benito Juárez) y posteriormente de 1877 a 1879 y un breve lapso en 1892 (ambos bajo el gobierno de Porfirio Díaz). Aunque los pormenores de su trabajo por esta dependencia del ejecutivo son amplios, sobresalen sus propuestas para gravar al comercio exterior, así como la imposición de nuevas modalidades tributarias, en las cuales predominó su visión de estimular el crecimiento nacional a partir de la explotación y exportación de los recursos naturales de México.

La obra refiere también lo que el historiador Daniel Cosío Villegas denominó "la aventura de Matías”, que representa su trayectoria como empresario cafetalero en Chiapas, así como su etapa de legislador en el Congreso de la Unión. Inmediatamente después centra su atención en tres temas medulares que comprenden la última etapa como diplomático de Matías Romero (1882-1898).

En primer lugar, detalla la negociación de un acuerdo de reciprocidad con Estados Unidos, preámbulo en muchos aspectos de lo que varias décadas después sería un acuerdo de libre comercio. Esta etapa como máximo representante diplomático ante los Estados Unidos, que concluye en 1898 con su deceso y con el otorgamiento de la categoría de embajada a la legación mexicana en ese país, exhibe a un diplomático que conoce a los principales actores, el funcionamiento del sistema político y los ámbitos de influencia de importancia para México, todo lo cual lo conjuga para asegurar la aprobación de un tratado bilateral que buscaba un marco propicio para el comercio a través de la desgravación arancelaria y la complementariedad que desde entonces se asumía entre ambas economías. Su urdimbre diplomática con legisladores y representantes de los partidos republicano y demócrata constata la visión de un hombre que 
interpretó el tiempo político y las circunstancias predominantes en el vecino país, en beneficio del nuestro, ello no obstante que el convenio no logró su aprobación definitiva en la Cámara de Representantes de los Estados Unidos.

Otro acontecimiento destacado que confirma su hechura de diplomático consumado es el establecimiento de los límites fronterizos con Guatemala, cuyas negociaciones se desarrollaron desde Washington y, en ciertas etapas, teniendo a Estados Unidos como mediador. En este caso, a la habilidad negociadora de Romero debe reconocerse su experiencia personal en el tema (empresario cafetalero/estudioso del desarrollo histórico de la frontera sur) y su motivación para llevar adelante esas negociaciones con éxito. Adicionalmente, es pertinente destacar su firme postura respecto a dejar al margen cualquier cuestionamiento a la posesión histórica y legal de Chiapas y el Soconusco, por parte de México, a fin de centrar la negociación exclusivamente en el establecimiento de los límites territoriales entre los dos países, aspecto que se logró con el acuerdo suscrito en 1882.

Por último, en el libro de Márquez y Silva Castañeda se exhiben también las dotes de Matías Romero como negociador en un ámbito multilateral trascendente: la I Conferencia Internacional Americana, celebrada en Washington entre 1889 y 1890, la cual buscaba formalizar un foro de coordinación entre los estados americanos, planteando entre otros temas una unión aduanera y la emisión de una moneda común. La experiencia y los contactos que tenía en Washington, su pleno dominio de la lingua franca que desde entonces predomina en la diplomacia, así como su habilidad negociadora, permitieron a Matías Romero fungir como vicepresidente de esta conferencia.

La conclusión de este esbozo de vida es que en la trayectoria diplomática de Matías Romero se conjuga lugar de origen, vicisitud histórica y pericia diplomática. Igualmente queda manifiesto que en la trayectoria hacia esa cúspide profesional toda escala en los ámbitos bilateral y multilateral, y de ser posible en otros ámbitos del servicio público, es algo fundamental para trascender la eterna cuestionante de asumirse "generalista o "especialista” en la labor diplomática. Con Matías Romero se constata el rasgo fundamental de cualquier diplomático: alta capacidad negociadora para lograr objetivos nacionales. En ese sentido la mejor referencia que se hace en la obra de este ilustre personaje proviene de un texto escrito en 1897 por José Martí, quien siendo periodista acreditado para la I Conferencia Internacional Americana, refirió: "no hay que buscar razones calladas a lo que no acepta, porque él da las que tiene, aunque parezcan nimias. Parezca lo que parezca, con tal de que quede servida la patria”.

Guillermo Gutiérrez Nieto Instituto Matías Romero Secretaria de Relaciones Exteriores ggutierrezn@sre.gob.mx 